\title{
A revolta das formigas: a insurreição de Labayu e seus filhos em EA 252-256*
}

\author{
The revolt of the ants: the insurrection of Labayu and \\ his sons in EA 252-256
}

\section{La revuelta de las hormigas: la insurrección de Labayu y sus hijos en EA 252-256}

\author{
Silas Klein Cardoso**
}

\begin{abstract}
RESUMO
A comunicação entre Labayu, rei siquemita, e seus filhos e a administração egípcia de el-Amarna demonstra as tensões, fragilidades e artimanhas políticas do período da Canaã dominada pelo Egito, no século 14 aEC. Além de serem fundamentais à reconstrução histórica do período, tais documentos apresentam um uso aprimorado da retórica. Nesse ínterim, este artigo oferece análise histórico-literária das cartas de EA 252-256. A partir da tradução, análise da estrutura retórica e exploração dos estudos de proveniência das tabuletas, oferecemos um comentário para tais documentos, elucidando o conteúdo e devidas implicações históricas. Ao final, apresentamos uma proposta de reconstrução histórica da revolta de Labayu.

Palavras-chave: Labayu; el Amarna; Canaã; Idade do Bronze; História.
\end{abstract}

\begin{abstract}
The communication between Labayu, King of Shechem, and his sons and the Egyptian administration of el Amarna, shows the tensions, fragilities and political deceits of the Egiptian dominion of Canaan in the $14^{\text {th }}$ century BCE. Besides fundamental to the historical reconstruction of the period, the documents presents an enhanced use of rhetoric. Thus, this article offers an historical-literary analysis of the letters EA 252-256. From the translation, analysis of rhetorical structure and exploration of the provenience studies of the tables, we offer a commentary to the documents, elucidating the content and its historical consequences. In the end, we present a proposal of historical reconstruction of the Labayu Revolt.

Keywords: Labayu; el Amarna; Canaã; Bronze Age; History.

\section{RESUMEN}

La comunicación entre Labayu, rey siquemita, y sus hijos y la administración egipcia de El Amarna demuestra las tensiones, fragilidades y artimañas políticas del período de Canaán dominado por Egipto en el siglo XIV aEC. Además, tales documentos presentan un uso peculiar de la retórica. Em esto, este artículo ofrece análisis histórico-literario de las cartas de EA 252-256. A partir de la traducción, análisis de la estructura retórica y explotación de los estudios de procedencia de las tabletas, ofrecemos un comentario para los documentos, aclarando el contenido y debidas implicaciones históricas. Al final, presentamos una propuesta de reconstrucción histórica de la revuelta de Labayu.

Palabras clave: Labayu; el Amarna; Canaán; Edad del Bronce; historia.
\end{abstract}

* Este artigo é parte da produção de pesquisa realizada durante o ano de 2017 pelo Grupo de Pesquisa "Arqueologia do Antigo Oriente Próximo", da Universidade Metodista de São Paulo - Reg. no CNPq $\mathrm{N}^{\circ} 4338921870858325$.

** Doutorando em Ciências da Religião (UMESP), bolsista CAPES. silasklein@gmail.com 


\section{Introdução}

As cartas de Labayu e Mut-Ba'lu (EA 252-254; 255-256) descrevem uma insurreição de Labayu, governante da cidade-estado de Siquém, e de seus filhos, provavelmente entre os anos 1350-1320 a.C. (cf. NA'AMAN 1992, p. 174), sob o governo de Amenhotep III ou Amenhotep IV (Akhenaten). Segundo Moran (1992, p. xxxvi), as cartas de Labayu pertenceriam ao estrato mais antigo de Amarna. Entretanto, como o arquivo foi escrito em apenas vinte anos (MYNÁROVÁ 2013, p. 347), é difícil precisar com certeza o desenvolvimento dos fatos.

Ao contrário do que se esperaria, o grande número de documentos num curto período não facilita a tarefa de reconstrução dos eventos históricos, pois a própria natureza das fontes traz algumas problemáticas que merecem ser observadas. Listamos algumas abaixo:

a) A falta de datação das cartas. Embora o conteúdo seja epistolar e dezesseis cartas sejam datadas, apenas quatro recebem datas concretas (EA 11; 23; 27; 254, cf. MYNÁROVÁ 2011, p. 123). A única carta de nosso grupo datada é $E A$ 254, mas contém um número de sinais ilegíveis, após a expressão $h \square t s p$, i.e., "ano real", o que já levou os pesquisadores a sugerir os anos "12" ou “32". As hipóteses de leitura alteram o reinado sob o qual se deu a revolta. Caso seja 12, poderíamos argumentar se tratar de Amenhotep IV/ Akhenaten e, caso seja 32, poderíamos argumentar ser Amenhotep III, partindo do estrato mais antigo das cartas. A convergência na saudação real de algumas cartas, entretanto, parece alocar as cartas na transição entre os dois reis. Duas cartas pertencentes a Akhenaten, trazem a saudação mencionando que o rei é "içado como o sol do céu" (EA 99; 367; 370), que encontram ressonância em $E A 366$, que estaria no meio da luta contra os insurgentes e $E A$ 267, que estaria depois dos problemas e antes de Milkilu perder a posse da terra (cf. EA 298) para Yahtiru, que teria sido trazido do Egito por Yanhamu ( $E A$ 290), o mesmo emissário real que recebe a carta de Mut-Ba'lu (EA 250) e que aflige Milkilu antes dele perder a posse da terra (EA 270-271; cf. 283). Antes disso, uma carta do rei a Milkilu, parece ter sido escrita por Amenhotep III, visto que glorifica Amun, não Aten, pela conquista do Alto Egito (EA 369, MORAN 1992, p. xxxvii). 
b) A falta dos destinatários do discurso. Como em toda peça comunicativa, emissor e destinatário são necessários à recomposição do discurso. O que nos sobrou da revolta de Labayu foram apenas cartas desordenadas que fazem menções a comunicações anteriores. As cinco cartas analisadas remetem a discursos previamente enviados pelo rei (EA 252:5-7; 253:7-10; 254:6-7) e seus oficiais (Ha’ya, 255:8-11; Yanḩamu, 256:4-7), o que dificulta sua recomposição. Embora, como parte da retórica da carta, a mensagem real seja reconstruída nesses momentos, ela é formatada a partir do interesse/ compreensão dos emissores (cf. abaixo).

c) O teor retórico das cartas. Se cartas, em geral, contém elementos retóricos que velam o real significado dos fatos por detrás da comunicação, momentos de tensão sócio-política tendem a mascarar ainda mais os fatos ocorridos. As cartas aqui apresentadas são relatos de governantes acusados de se revoltarem contra o rei do Egito que foram pegos e precisarão prestar contas ante seu senhor (cf. $E A$ 263). Por isso, o teor de bajulação, se já estereotipado nas cartas comuns, tende a ser mais intenso, mascarando o que realmente teria acontecido: em EA 252, Labayu aceita as ordens do rei sob controvérsia; em EA 253 e EA 255 tratam da família como meio de argumentação para receber favores; em EA 254 Labayu oferece a esposa e a própria vida como garantias de sua lealdade; e em $E A$ 256, Mut-Ba'lu parece fazer uma ameaça velada de sua coligação anti-Egito, dizendo que se uniu contra um certo número de cidades. A escrita também pertence a uma tradição multiétnica e internacional, que afeta a expressão dos atores do processo comunicativo.

Se o descrédito da retórica de Labayu e de seus filhos pôde ser elencado, também é verdade que a denúncia das atitudes de Labayu por alguns dos governantes rivais de cidades-estado ajuda a perceber o outro lado da questão com maior clareza. Embora tenham que ser observados com os mesmos olhares de suspeita, Biridyia (EA 244-240), Ba'lu-UR.SAG (EA 249-250), 'Abdi-Heba (EA 289) e, após a morte de Labayu, Shuwardata (EA 280), caracterizam o rei Labayu e seus filhos como insurgentes que se aliaram com grupos marginalizados para tentar acabar com o governo egípcio na terra (EA 246). Embora os acontecimentos sejam fugidios, a caracterização do rei siquemita parece ter se transformado em narrativa exemplar do período. A seguir, tentamos elucidar a situação da análise do conteúdo e retórica das cartas do conjunto. 


\section{Metodologia}

Nossa metodologia consistiu na tradução, análise da estrutura retórica das cartas, estudos exploratórios sobre a proveniência das tabuletas e um comentário para cada documento. Algumas palavras tornam-se necessárias sobre cada um desses passos traçados.

A presente tradução foi realizada a partir dos textos críticos em inglês de Moran (1992) e Rainey (2015), priorizando as opções do texto crítico mais recente e reconhecido de Rainey (2015). Além da tradução, foram realizadas uma série correções à sintaxe portuguesa e adaptações dos sentidos dos ideogramas diretamente do canano-acádico pelo autor do artigo.

Para a análise da estrutura retórica das tabuletas, utilizamos o estudo de Jana Mynárová (2007) sobre a retórica diplomática das cartas de Amarna. Nisso, seguimos a indicação da autora de não anotar apenas os itens padronizados, mas os elementos únicos e variações da fraseologia padrão. Os elementos padrões das cartas acádias, assim, estão representados pela enumeração em letras minúsculas (p.ex., "a) cabeçalho”, “b) conteúdo” etc), com as subdivisões nos subtópicos correspondentes (p.ex., "fórmula de saudação", "fórmula de prostração" etc).

Entretanto, a terminologia técnica do estudo de Mynárová impede-nos de visualizar a vivacidade e conflito dentre as cartas de Labayu. Afim de auxiliar o leitor a perceber a tensão nas cartas, utilizamos experimentalmente subdivisões com terminologias da retórica clássica, que oferecem melhor subsídio à análise do pathos envolvido na comunicação. Seguimos, para isso, as designações dos estudos de Barthes (2001, p. 48-100) e Reboul (2004, p. 43-69).

Para verificar a proveniência das cartas, utilizamos das pesquisas de Goren, Finkelstein e Na'aman $(2002,2004)$. Tentamos, com isso, alocar as cartas dentro de seu quadro geográfico mais amplo, para compreender as implicações da origem das cartas e, também, estabelecer uma datação. Esse movimento foi especialmente importante nas cartas de Mut-Ba'lu (EA 255-250).

Nosso comentário, além de analisar os elementos acima dispostos, discute a intertextualidade entre os outros documentos do arquivo e implicações históricas. Ao final do texto, oferecemos uma análise histórica abrangente do período, tentando interpretar o conjunto de cartas.

\section{EA 252: Vigilância mesmo sob discórdia}

\section{Tradução EA 252}

(1-4) Diga ao rei, meu senhor, a mensagem de Lab'ayu, seu servo. Aos pés do meu senhor tenho caído.

(5-9) Quanto ao senhor ter escrito a mim, "Mantenha vigilancia sobre os homens que tomaram a cidade", como eu posso manter vigilância sobre os homens? Com violência a cidade foi tomada. 
(10-13) Quando eu jurei meu voto de paz — e o oficial sênior o fez comigo — a cidade foi tomada e meu Deus.

(13-15) Minha difamação foi expressa (eu fui difamado) diante do rei, meu senhor.

(16-19) Ademais, quando formigas são feridas, elas não apenas retiram-se, mas elas mordem as mãos do homem que as feriu.

(20-22) Como sou pressionado neste tempo! E duas de minhas cidades foram tomadas.

(23-31) Ademais, se proferires o comando, "Caia debaixo deles para que possam feri-lo", eu certamente manterei vigilância sobre meu inimigo, os homens que tomaram a cidade e meu Deus, os saqueadores de meu pai! E eu certamente manterei vigilância sobre eles!

\section{Estrutura $E A 252$}

a) Cabeçalho: de Labayu ao rei do Egito (1-4)

Fórmula de abertura (remetente/destinatário): Diga ao rei... (1-3a)

Saudação: de Labayu, seu servo (3b)

Prostração: aos pés do rei (4b)

b) Conteúdo: vigilância mesmo em discórdia (5-31)

Exórdio: sobre o pedido real (5-9)

Narração e confirmação: exposição de conflitos (10-13)

Peroração: a situação de Labayu e o aceite (14-31)

Amplificação: justificativas de demora ao aceite (13-22)

Paixão: exagero retórico para comoção (23-30)

Recapitulação: aceite do pedido real (31)

\section{Proveniência EA 252}

A análise petrográfica de $E A 252$ demonstrou que a argila da tabuleta deve ter vindo das proximidades do assento real de Labayu, Siquém. Os dados petrográficos são ricos e confirmam a localidade da região central, especificamente, nas proximidades de Jebel Kebir, $5 \mathrm{~km}$ ao nordeste de Siquém (GOREN \& FINKELSTEIN \& NA'AMAN, 2004, p. 264).

\section{Comentário EA 252}

A carta $E A 252$ reage a uma orientação real, solicitando que Labayu mantenha olhos abertos frente a alguns invasores que teriam tomado duas cidades. Ao que parece, a disposição de Labayu em defender essas cidades estava sendo questionada, pela reclamação de que fora difamado, provavelmente por um emissário real (MORAN 1992, p. 306). Talvez, para o rei, essas cidades fossem pagamento pelo início do motim contra o rei do Egito (cf. EA 240). Assim, ele reage dizendo que a cidade teria sido tomada com violência e não apenas doada. Talvez, a carta reflita o ambiente de conflito presente em EA 287, quando 'Abdi-Heba de Jerusalém diz que os filhos de Labayu com Milkilu deram terras para os 'Apiru.

A invasão, segundo Labayu, teria sido especialmente dolorosa para ele pela conquista da cidade do Deus (estátua) do pai de Labayu. Então se caracterizaria como profanação do próprio espaço familiar de Labayu e teria que ser recompensada. Assim, mesmo contradito pelo emissário real, que 
estaria com Labayu quando do acordo de paz que teria sido violado, Labayu se dispõe à tarefa. Entretanto, ele não deixa de assinalar sua revolta: ele revidará àqueles que tentarem dominá-lo. Aqui, parece haver uma ameaça velada ao próprio rei do Egito.

É particularmente estranha a redução da fórmula de prostração. Enquanto nas demais cartas ela se dá "sete vezes e mais sete", aqui ela aparece como prostração comum. Talvez o estado de espírito de Labayu tenha afetado o ditado da carta ou, talvez, ele queira com isso apontar sua insatisfação com a difamação. De qualquer forma, a carta assemelha-se mais a uma enviada a um rei comum de segundo escalão (cf. EA 256).

\section{EA 253: "Não sou criminoso/malfeitor!"}

\section{Tradução EA 253}

(1-6) [Ao meu r]ei, me[u SENHOR] e meu Deus-Sol, assim diz [La]b'ayu teu [servo] e a p[oeira], [aquela] que [pis]as; [ao]s pés do [re]i, meu SENHOR, sete v[eze]s e mais sete tenho caído.

(7-17) [Eu tenho ouv]ido as palavras [as quais] o rei, meu senhor (lit. de acordo com teu estômago/coração) numa [tab]uleta escreveu [par]a mim. [Veja], eu sou um servo do rei [como] meu [pa]i e como o [pa]i do meu pai foi servo do rei anterior antigo e não me rebelei e eu não fui um malfeitor.

(18-31) Observe meu crime e observe a minha malfeitoria de que eu teria entrado na cidade de Gezer e para eles teria falado assim: "Este rei está nos punindo?" Agora, para mim, não há outra intenção, senão servir ao meu rei. E qualquer outra coisa que decida dizer o rei, eu atentarei.

(32-35) $[\mathrm{Qu}]$ e possa me atribuir o rei ao [encar]go do meu oficial real [em ordem de] proteger a ci[dade do rei].

\section{Estrutura EA 253}

a) Cabeçalho: de Labayu ao rei do Egito (1-6)

Fórmula de abertura (remetente/destinatário): Ao rei... (1-2a)

Saudação: de Labayu, seu servo (2b-3a)

Prostração: aos pés do rei (3b-6)

b) Conteúdo: "não sou criminoso/malfeitor!" (7-35)

Exórdio (5-17):

Sobre a carta real (5-9)

Declaração de fidelidade (10-17)

Narração e confirmação: exposição de conflitos (18-26)

Peroração: a prova da fidelidade (27-35)

Amplificação: declaração de fidelidade (27-28)

Paixão: exagero retórico para comoção (29-31)

Recapitulação: prova da fidelidade (32-35)

\section{Proveniência $E \boldsymbol{A} 253$}

A tabuleta foi analisada petrograficamente (GOREN \& FINKELSTEIN \& NA'AMAN, 2004, p. 264) e demonstrou traços característicos de rendzina com alguma terra rossa. Os dois tipos de solo são encontrados na 
região central, especialmente próximos a Tell Balaṭa, Siquém. Entretanto, os materiais são distintos, por algum motivo, de $E A 252,254$. Os materiais são mais próximos de Siquém do que os de $E A$ 252, 254.

\section{Comentário EA 253}

A segunda carta de Labayu ao rei do Egito modifica-se primeiramente na forma de prostração. Agora ele cai "sete vezes e mais sete" ao pé do Faraó e passa a ser a "poeira dos pés que o rei pisa". A bajulação inicial demonstra a vontade de reestabelecer os laços diplomáticos, após o conflito inicial. É apontado um problema grave na relação entre o soberano egípcio e o vassalo cananita: um motim teria iniciado em Gezer, que era provavelmente controlada por Milkilu (EA 249; 251; 268), no qual Labayu teria se mostrado insatisfeito com o governo.

Labayu argumenta dizendo que sua dinastia teria boas relações com o governo egípcio desde muitos anos e desde os faraós anteriores. Talvez aqui esteja implícita uma troca de governo não muito antiga. As ações do rei de Siquém, entretanto, lhe teriam feito ganhar fama de "criminoso" e "malfeitor" no Egito, que corresponderiam a crimes tanto políticos quanto religiosos, pela natureza das relações com o Faraó. A carta se encerra com um pedido de que o rei permita que proteja a cidade, agora chamada "do rei". Aparentemente, Labayu já estava sofrendo um início de embargo egípcio, perdendo privilégios por sua cidade central.

\section{EA 254: “Quem sou eu para tomar terras reais!"}

\section{Tradução EA 254}

(1-5) Ao rei, meu senhor e meu Deus-Sol, assim diz Lab'ayu, teu servo e a poeira, aquela que pisas: aos pés do rei, meu senhor e meu Deus-Sol, sete vezes e mais sete tenho caído. (5-10) Tenho ouvido as palavras que o rei enviou para mim. E quem sou eu para que o rei perca suas terras por minha causa?

(10-15) Veja, sou um servo leal do rei e eu não sou um criminoso [cf. ak. arnu] e eu não sou um malfeitor [c.ak. hatûu] e não retive meu tributo e não retive o pedido de meu homem, oficial sênior.

(16-29) Agora, tenho sido difamado e injuriado e nem mesmo conferiu o rei, meu senhor, se realmente sou culpado! Ademais, meu erro é que simplesmente entrei na cidade de Gezer e estava dizendo: "Totalmente, as minhas posses tomou o rei, mas as posses de Milkilu, onde estão? Sei os feitos de Milkilu contra mim."

(30-37) Ademais, sobre o meu filho, que o rei escreveu. Eu não sabia que meu filho, com os homens 'Apiru estava associado, mas veja, eu não entreguei ele na mão de Addaya?

(38-46) Ademais, se para minha esposa o rei tivesse escrito, como poderia retê-la? Pois se para mim o rei tivesse escrito "Coloque uma adaga de bronze em seu coração e morra", como não cumpriria a palavra do rei?

Ano $10+2(+x ?)$ 


\section{Estrutura EA 254}

a) Cabeçalho: de Labayu ao rei do Egito (1-6)

Fórmula de abertura (remetente/destinatário): Ao rei... (1-2a)

Saudação: de Labayu, seu servo (2b)

Prostração: aos pés do rei (3-5)

b) Conteúdo: “quem sou eu pra tomar terras reais?" (7-46)

Exórdio (6-10a):

Sobre a carta real (6-7)

Proposição "quem sou eu para tomar terras reais?” (8-10a)

Narração e confirmação: exposição de conflitos (10b-37)

Argumento 1: Não sou criminoso/malfeitor (10b-15)

Argumento 2: Tenho sido difamado (16-29)

Argumento 3: Não sabia de meu filho com os 'Apiru (30-37)

Peroração: exageros retóricos para comoção (38-46)

c) Observação: Ano 10+2

\section{Proveniência EA 254}

A análise petrográfica (GOREN \& FINKELSTEIN \& NA'AMAN, 2004, p. 264) mostrou traços similares aos encontrados em EA 252, com formações de moza e 'Amminadav e, provavelmente, sendo geridas de Jebel Kebir, alguns quilômetros distantes de Siquém.

\section{Comentário EA 254}

A última carta de Labayu ao rei do Egito parece refletir o avanço das notícias de sua insurgência. Algumas outras cartas do conjunto tratam do assunto: em EA 244, Biridiya de Megiddo diz que Labayu pretende tomar Megiddo das mãos reais e, em E $A$ 246, o mesmo governante diz que os dois filhos de Labayu contrataram 'Apiru e Sutû para fazer guerra contra o local; em EA 250, Ba'lu-UR.SAG de Rehov, diz que os filhos de Labayu querem tomar as terras do rei; em EA 287, 'Abdi-Heba de Jerusalém diz que os filhos de Labayu com Milkilu deram terras para os 'Apiru e em EA 289, diz que os filhos de Labayu querem a terra para eles. Algumas dessas falas teriam chegado ao ouvido real, que logo reclamou de Labayu querer tomar as terras dele, provavelmente algum tempo depois de as ter cedido (cf. acima EA 252).

A exposição de Labayu, então, utiliza três argumentos-chave para tentar dissuadir a vontade real. O primeiro apela para o rigor jurídico da relação: Labayu não teria retido o tributo ou o pedido do emissário. Aparentemente, além da cidade tomada, o tributo não teria chegado ao rei do Egito, o que seria uma declaração de guerra contra o soberano. 
O segundo argumento atinge o ethos daqueles que teriam levado a notícia ao faraó. Labayu reclama que os fatos não teriam sido conferidos pelo rei: ele havia apenas confiado em seus emissários e, a partir disso, escrito suas considerações. Os problemas com comissários parecem ter sido grandes na época $(E A 270-271)$ e sua palavra era importante ao rei $(E A 207 ; 213 ; 283)$. Um de seus emissários, Yanhamu, é chamado de "carregador de guarda-sol" do rei (EA 106). A razão para a difamação, além disso, era novamente algo dito em Gezer, de Milkilu. Labayu tenta inverter a revolta para atingir seu rival Milkiltu (EA 254:24-29), cujas posses não teriam sido tomadas, o que nos faz supor que as posses de Labayu haviam sido tomadas.

O terceiro argumento é sobre a ligação do filho de Labayu com os 'Apiru. A conexão já havia sido anunciada em duas outras cartas ( $E A$ 246; 287) e intuída na primeira carta de Labayu ( $E A$ 252). O rei, então, diz que o havia entregado nas mãos de Addaya, emissário egípcio, provavelmente para ser levado ao Egito e responder pelos seus crimes.

O rei despede-se deixando claro que faria qualquer coisa pelo rei. Como mote para a entrega de seu filho, ele diz que entregaria sua esposa e até mesmo sua própria vida, caso fosse o que o rei pedisse a ele.

\section{EA 255: "não sou digno de despachar caravanas?"}

\section{Tradução EA 255}

(1-7) Diga ao rei, m[eu] senhor e meu Deus-Sol, a mensagem de Mut-Ba'lu, seu servo, poeira de seus dois pés e a poeira, aquela que pisas: aos pés do meu senhor, sete vezes e mais sete tenho caído.

(8-11) O rei, meu senhor, enviou para mim Ha'ya, para dizer: "Caravanas para a terra de Hanigalbat, veja, eu estou enviando; então despache-os!”

(12-14) Quem sou eu para que não possa despachar caravanas do rei, meu senhor?

(14-21) Veja, [La]b’ayu, meu pai, [sempre ser]viu ao rei, seu senhor, [e ele] sempre despachou [todas as carava]nas que o rei [deveria] enviar para a terra de Hanigalbat e para a terra de Karaduniyash.

(22-25) Que possa o rei, meu senhor, despachar caravanas! Eu irei transportá-las sob guarda pesada.

\section{Estrutura EA 255}

a) Cabeçalho: de Mut-Ba'lu ao rei do Egito (1-7)

Fórmula de abertura (remetente/destinatário): Ao rei... (1-3)

Saudação: de Mut-Ba'lu, seu servo (3-4)

Prostração: aos pés do rei (4b-7)

b) Conteúdo: "não sou digno de despachar caravanas? " (8-25)

Exórdio (8-14):

Sobre a carta real (8-11)

Proposição "não sou digno de despachar caravanas?" (12-14a) 
Narração: “meu pai sempre despachou caravanas..." (14b-21)

Peroração: pedido ao rei para despachar caravanas (22-25)

\section{Proveniência EA 255}

A análise petrográfica de EA 255 (GOREN \& FINKELSTEIN \& NA'AMAN, 2004, p. 261) demonstrou que a carta contém traços característicos do Vale do Jordão. Entretanto, alguns indícios de basalto demonstram que ela deve ter sido enviada de Betsã ou Rehov.

\section{Comentário EA 255}

A carta de EA 255 é a primeira encontrada que teria sido escrita segundo Mut-Ba'lu. Aparentemente, o embargo criado pelo rei egípcio a Labayu e seus filhos continuava, quando estes alcançaram o poder em Pihilu (Pela), na fronteira transjordaniana com Betsã. A questão levantada é o pedido para o despacho comercial de Pihilu até Ḩanigalbat. Hanigalbat era uma designação para a região de Mitanni, entre Síria e Assíria, na confederação de estados Hurritas (MORRISON 1992, p. 874). O prolífico comércio talvez tivesse sido retirado de Mut-Ba'lu, talvez pela sua associação com a revolta de seu pai, Labayu ou, talvez, o pedido de Ha'ya fosse condescendente, demonstrando a inabilidade de Mut-Ba'lu de manter o comércio.

De qualquer forma, a figura de Labayu é evocada por Mut-Ba'lu, seu filho, dizendo que Labayu sempre tinha sido responsável por despachar caravanas para Hanigalbat e Karaduniyash, que seria a Babilônia. Mut-Ba'lu, então, solicita permissão ao rei para despachar caravanas para a região e diz que as guardaria. Talvez aqui a condescendência do pedido fique evidente, demonstrando que o medo era de que as caravanas se perdessem, talvez vendidas, como as terras haviam sido vendidas por Labayu aos 'Apiru (EA 252).

\section{EA 256: “como posso ter fugido dos emissários reais?”}

\section{Tradução EA 256}

(1-4) Diga para Yanhamu, meu SENHOR, a mensagem de Mut-Ba'lu, teu servo, aos dois pés do meu senhor tenho caído.

(4-10) Como é dito em tuas faces: Mut-Ba'lu fugiu; e Ayyab escondeu'? Como pode o rei da cidade de Pihilu fugir da presença dos emissários/governadores do rei, seu senhor?

(10-14) Como o rei, meu senhor, vive, como o rei, meu senhor, vive, (eu juro) que se Ayyab está na cidade de Pihilu, veja, não será por dois meses!

(15-19) Veja, Bin-'ilîma pediu (por ele)! Veja, [T]adu pediu (por ele)! Veja, Yashuya pediu (por ele)!

(19-28) No mais, do mercado de Shullum-Marduk, fui ao socorro de Ashtaroth, quando se tornaram hostis todas as cidades do território de Garu: a cidade de Udumu, a cidade de Aduru, a cidade de Araru, a cidade de Mishta, a cidade de Magdal, a cidade de 'Êni-'anabi, a cidade de Zarqu. A cidade de 'Ayyôni e a cidade de Yôbilu foram tomadas. 
(29-35) No mais, veja, após você me enviar a tabuleta, eu escrevi para ele. Antes de você chegar de sua campanha, então veja, ele terá vindo para a cidade de Piḩilu e certamente eu obedecerei suas ordens.

\section{Estrutura EA 256}

a) Cabeçalho: de Mut-Ba'lu a Yanḩamu (1-4)

Fórmula de abertura (remetente/destinatário): a Yanḩamu... (1-2) Saudação: de Mut-Ba'lu, seu servo (2b-3a)

Prostração: aos pés do rei (3b-4a)

b) Conteúdo: “como posso ter fugido dos emissários do rei? " (4b-35) Exórdio (4b-10a):

Sobre o problema levantado (em carta?) (4b-7a)

Proposição "como posso ter fugido dos emissários do rei?” (7b-10a) Narração (10b-31):

Argumento 1: Ayyâb não estará aqui por mais de dois meses (10b-14) Argumento 2: Recebi os emissários (Bin-'ilîma, Tadu, Yashuya) (15-19a) Argumento 3: Apenas saí em apoio a Ashtaroth (19b-28)

Argumento 4: Já escrevi para ele sobre o problema (29-31)

Peroração (32-35): antes de chegar da campanha, ele estará aqui (32-35)

\section{Proveniência EA 256}

A análise petrográfica de EA 256 (GOREN \& FINKELSTEIN \& NA'AMAN, 2004, p. 260-261) demonstrou que a carta contém traços característicos do Vale do Jordão. Ao contrário de EA 255, entretanto, ela demonstra traços locais, especificamente de Tell Abu al Kharaz, próximo a Pihilu. Assim, ela provavelmente foi escrita e enviada de Pella.

\section{Comentário EA 256}

A última carta de Mut-Ba'lu no registro de Amarna é para um dos emissários do rei egípcio em Canaã: Yanḩamu. Yanḩamu é chamado de "carregador de guarda-sol" do rei em uma carta (EA 100) e parece que vai se tornando, com o passar do tempo, mais importante. Na época dos filhos de Labayu, ele é o encarregado de toda a região ( $E A$ 215; 283; 290) e parece já ter poder suficiente para oprimir aos governantes locais, talvez a mando do rei, como acontece com Milkilu (EA 170-171), talvez pela associação aos filhos de Labayu (EA 287; 289).

A acusação é que Mut-Ba'lu teria fugido e escondido Ayyab, o rei de Ashtaroth, que havia cometido algum crime contra a Babilônia (EA 364; MORAN 1992, p. 310). A intenção da carta enviada por Yanḩamu era verificar a quem o rei de Pihilu estava inclinado. Então, ele argumenta dizendo 
que, primeiro, se estivesse, isso não duraria mais de dois meses. Segundo, ele não aceita a acusação de que estaria se escondendo para ocultar Ayyab, mas que recebeu três emissários solicitando a entrega de Ayyab: Bin-'ilîma, Tadu, Yashuya.

Terceiro, que ele havia saído para Ashtaroth apenas como apoio às cidades do rei. Ele cita, então, as cidades, para demonstrar que estava protegendo o território real e não se aliando a um terceiro poder que queria tomar o trono. As cidades são do território de Garu, que Benjamin Mazar identificou com a bíblica Gesur (Js 13,2, 11-13), que seria um centro administrativo em Golan no século 14 aC. (BRUEGGEMANN, 2016): Udumu, Aduru, Araru, Mishta, Magdal, 'Êni-'anabi, Zarqu, 'Ayyôni e Yôbilu, todas ao redor do bíblico Quinerete.

O último argumento é, na verdade, um pedido de confiança: Mut-Ba'lu afirma que terá entregue Ayyab para o rei antes que a campanha (lit. caravana militar) chegue a Pihilu.

\section{Reconstrução histórica}

O primeiro grupo (EA 252254) é de cartas pertencentes a Labayu de Siquém, enquanto o segundo grupo são cartas pertencentes ao seu filho, Mut-Ba'lu, de Pihilu (Pella).

As cartas de Labayu não demonstram a cidade de origem do governante. Entretanto, algumas cartas ajudam a inferir seu local de origem. EA 289:18-24, especificamente, fala de quando Labayu entregou a cidade de Siquém aos 'Apiru por dinheiro, uma referência que parece coadunar ao evento histórico da revolta de Labayu e as acusações de Biridyia (EA 246). Embora não sejam locais, a argila utilizada nas cartas de Labayu aproximam-se de Siquém como local de origem (cf. "Proveniência”, EA 252-254). As cartas de

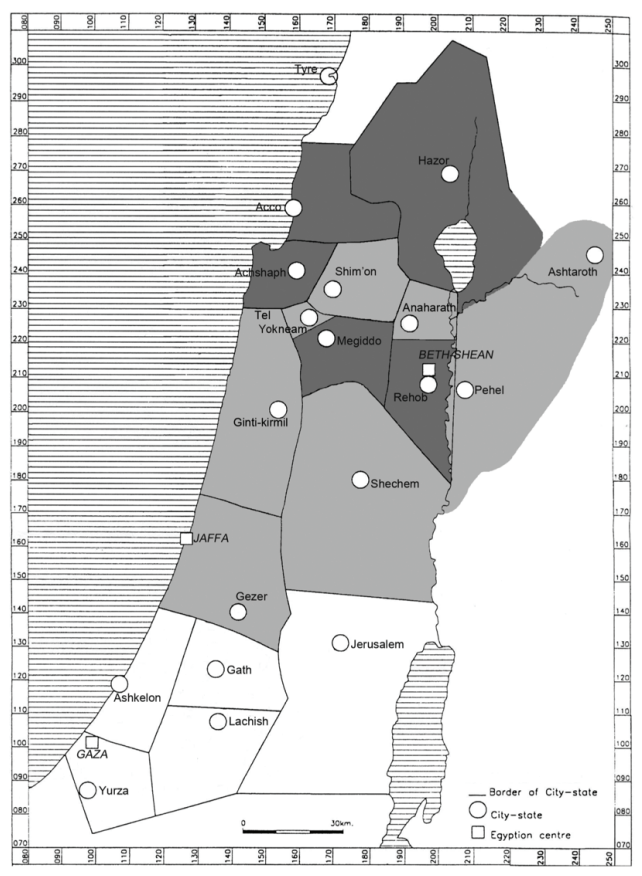

Figura 1. Coalizão pró-siquém: Gezer (Milkilu); Ginti-Kirmil (Tagi); Tel Yoqneam (Ba'lu-mehir; Anaharath (Bayadi e Baduzana); Pihilu (Mut-Ba'lu); Ashtaroth; Shim'on. Coalizão anti-siquém: Megiddo (Biridiya); Rehob (Ba'lu-UR.SAG); Acsaf e Aco; Gath; Hazor. Imagem: FINKELS-TEIN 2015, p. 15 
Mut-Ba'lu, por sua vez, tratam de negócios locais e ajudam a mostrar claramente sua origem, que coadunam à análise petrográfica de $E A 256$, enquanto EA 255 teria sido enviada de Betsã (cf. acima).

As cartas, de forma geral, demonstram a tensão entre o líder siquemita e o rei do Egito, por causa de um motim. Aparentemente, Labayu estava procurando descer e conquistar o Vale de Jezreel e chegou a sitiar Magidda (i.e., Meggido, cf. EA 244-245). Os dois filhos de Labayu, nisso, teriam contratado 'Apiru e os homens de Sutû (EA 246) para se levantar contra o rei.

Uma coalizão teria sido formada contra o rei egípcio (FINKELSTEIN \& NA'AMAN 2006, p. 174-177; cf. GOREN \& FINKELSTEIN \& NA'AMAN 2002; cf. Figura 1), entre: (a) Gezer de Milkilu (EA 250:32-39, 53-56; 289:25-36; 287:25-32); (b) Ginti-Kirmil de Tagi, o sogro de Milkilu (EA 249:4-10) (cf. EA 263:33-34; 289:18-20); (c) Tel Yoqneam de Ba'lumehir (EA 245:36-45); (d) Anaharath de Bayadi e Baduzana, que eram próximos (EA 237-238); (e) Pihilu, do filho de Labayu, Mut-Ba'lu (EA 255; cf. 250:35-38); (f) Ashtaroth, que teria sido salva por Mut-Ba'lu e teria se tornado aliada (EA 256; cf. 364); e (g) Shim'on, de onde o governante teria ido prestar contas ao Egito por sua aliança com Siquém (EA 263).

Foi encontrado um documento cuneiforme em Betsã que parece ter sido comunicação privada entre Tagi e Labayu durante a revolta (HOROWITZ \& OSHIMA 2006, p. 48-49):

\section{Texto cuneiforme}

1. a-na La-ab-a-「yaר

2. be-li-ia

3. qi-bi-ma

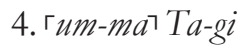

5. a-na LUGAL EN-

6. \li-ia

7. iš-te-me $\check{s} a$

8. \pár-ka a-na

9. $\ulcorner i a\urcorner-s i$ **

10-12. tracos

\section{Tradução}

Para Labayu meu senhor, diga.

Mensagem de Tagi:

Ao rei (Faraó) meu senhor:

Eu tenho ouvido atentamente à sua expedição para mim...

traços

Além dos nomes pertencerem aos personagens da insurreição de Labayu, também é interessante o objeto com a escrita. Segundo Horowitz e Oshima, trata-se de um selo cilíndrico. Essa forma não era usual para comunicação real e parece ter sido escolhida para ajudar no teor secreto da coalizão sique- 
mita contra os egípcios. O fato dela ter sido encontrada em Betsã também é revelador, visto ser de um entreposto ou guarnição na entrada do Vale de Jezreel que, segundo EA 244-246, era um dos alvos principais de Labayu, talvez pela prosperidade da região e a possibilidade de se conquistar todo o terreno tendo em mãos o celeiro da região.

Talvez esteja relacionada, também, a situação de EA 280, quando Shuwardatu de Gath e 'Abdi-Heba de Jerusalém disputam a Shefelah. Shuwardatu chega a utilizar a situação de Labayu para conspirar contra 'AbdiHeba. Primeiro, ambos estão unidos contra os 'Apiru, isto é, os rebeldes que queriam tomar as terras do rei (EA 360), mas, logo depois, Shuwardatu chama 'Abdi-Heba de Labayu (EA 280), pedindo permissão para guerrear contra os homens de Qeltu (EA 287; 289). Aparentemente, a situação logo foi conhecida e replicada e os efeitos, nas guerras pela Shefelah, foram ainda mais severos (cf. EA 278; 279; 282; 283; 284).

De qualquer forma, no caso de Labayu e seus filhos, uma coalizão contrária, encabeçada por Biridyia de Magiddo, teria se erguido (FINKELSTEIN \& NA'AMAN, 2006, p. 177-179), contando com: (a) Megiddo de Biridiya (EA 244-246); (b) Rehob de Ba'lu-UR.SAG (EA 249-250); (c) Acsaf e Aco (EA 366; 245); (d) Gath (EA 280); (e) Hazor (EA 364).

A coalizão não se encerrou com a morte de Labayu (EA 280) pelo povo de Gina (EA 250:15-27), atual Jenin e Beth-Haggan bíblica (2Rs 9.27, cf. ZERTAL 1992), transferindo a guerra aos seus filhos, que continuaram a angariar membros para sua revolta (EA 250:37-39), também centrada em Pella (EA 255-256). Entretanto, aparentemente a insurreição acabou de forma trágica. O estrato XIII (1400-1310 aC) de Tell Balâtah (Siquém), que equivale ao período da correspondência de Amarna, encerra-se destruído por fogo no período. Nos outros estratos (XII-XI, 1200-1100 aC), a cidade perde poder político (cf. CARDOSO 2015, p.67), que parece denotar o fim da insurreição siquemita como um todo.

\section{Referências bibliográficas}

BARTHES, R. A aventura semiológica. São Paulo: Martins Fontes, 2001.

BRUEGGEMANN, D. A. Geshur. In: BARRY, J. D. et al. (orgs). The lexham Bible dictionary. Bellingham: Lexham Press, 2016. [ebook]

CARDOSO, S. K. Siquém, símbolo de Israel Norte. Caminhando, São Bernardo do Campo, v. 20, n. 2, jul/dez, p. 59-71, 2015.

GOREN, Y.; FINKELSTEIN, I.; NA'AMAN, N. (eds.). Inscribed in clay: provenance study of the Amarna Letters and other ancient Near Eastern texts. Tel Aviv: Tel Aviv University, 2004. 
GOREN, Y.; FINKELSTEIN, I.; NA'AMAN, N. The seat of three disputed canaanite rulers according to petrographic investigation of the Amarna Tablets. Tel Aviv, v. 29, p. 221-237, 2002.

FINKELSTEIN, I. The last Labayu: king Saul and the expansion of the first north israelite territorial entity. In: AMIT, Y.; BEN ZVI, E.; FINKELSTEIN, I; LIPSCHITS, O. (eds.). Essays on ancient Israel in its Near Eastern context. A Tribute to Nadav Na'aman. Winona Lake: Eisenbrauns, 2006, p. 171-187.

FINKELSTEIN, I.; NA'AMAN, N. Shechem of the Amarna Period and the rise of the Northern Kingdom of Israel. In: CZERNY, E. et al. (eds.). Timelines: studies in honor of Manfred Bietak. Vienna: Peeters, 2006, p. 349-356.

HOROWITZ, W.; OSHIMA, T. Cuneiform in Canaan: cuneiform sources from the land of Israel in ancient times. Jerusalem: Israel Exploration Society, 2006.

MORAN, W. L. The Amarna letters. Baltimore: Johns Hopkins, 1992.

MORRISON, M. A. Mitanni. In: FREEDMAN, D.N. (org.) The Anchor Yale Bible Dictionary. Vol. 4. New York: Doubleday, 1992, p. 874-876.

MYNÁROVÁ, J. Amarna Letters. In: BAGNALL, R; BRODERSEN, K.; CHAMPION, C. ERSKINE, A.; HUEBNER, S. (eds.). The Encyclopedia of Ancient History. Vol. 1. Malden; Oxford; Carlton: Wiley-Blackwell, 2013, p. 347-348.

MYNÁROVÁ, J. Expressions of dates and times in the Amarna Letters. Ägypten un Levante, v. 21, p. 123-128, 2011.

MYNÁROVÁ, J. Language of Amarna - Language of diplomacy: perspectives on the Amarna Letters. Praga: Czech Institute of Egyptology, 2007.

NA'AMAN, Nadav. Amarna Letters. ABD. New York: Doubleday, 1992, v. 1, p. 174.

RAINEY, A. (aut.); SCHNIEDEWIND, W.; COCHAVI-RAINEY, Z. (eds.). The El-Amarna correspondence: a new edition of the cuneiform letters from the site of El-Amarna based on collations of all extant tablers. Leiden; Boston: Brill, 2015.

REBOUL, O. Introdução à Retórica. São Paulo: Martins Fontes, 2004.

ZERTAL, A. Beth-Haggan (Place). In: FREEDMAN, D. N. (ed.). The Anchor Yale Bible Dictionary. New York: Doubleday, 1992, v. 1, p. 687.

Submetido em: 11-5-2018

Aceito em: 24-5-2018 